\title{
siRNA-based targeting of fractalkine overexpression suppresses inflammation development in a severe acute pancreatitis rat model
}

\author{
LIYA HUANG $^{1,2}$, JUNWEN MA ${ }^{1,3}$, YUMING TANG $^{1}$, PING CHEN $^{1}$, SHUXIAN ZHANG $^{1}$, \\ YONGPING ZHANG ${ }^{1}$ and YAO ZONG YUAN ${ }^{1}$ \\ ${ }^{1}$ Department of Gastroenterology, Ruijin Hospital, Shanghai Jiaotong University \\ School of Medicine, Shanghai 200025, P.R. China
}

Received January 5, 2012; Accepted February 28, 2012

DOI: $10.3892 /$ ijmm.2012.1050

\begin{abstract}
Fractalkine (FKN), a chemokine that acts as both an adhesion molecule and a chemoattractant, is expressed in many inflammatory diseases. Chemokines play a crucial role in severe acute pancreatitis (SAP). This study used adenovirusmediated siRNA to target FKN overexpression and assessed its ability to suppress inflammation development in a SAP rat model. Adenovirus-mediated FKN siRNA was transfected into cerulein-stimulated AR42J cells. The growth of ceruleinstimulated AR42J cells was determined by colony formation and MTT assays. The inhibitory effect of the FKN siRNA was studied in a SAP rat model in vivo and detected by ELISA, RT-PCR, western blot analysis and immunohistochemistry. FKN, IL- 8 and TNF- $\alpha$ were found to be overexpressed in cerulein-stimulated AR42J cells by ELISA and western blot analysis $(\mathrm{P}<0.05)$. The animal experiments confirmed that FKN siRNA could inhibit inflammation development in SAP. The values of serum FKN, TNF- $\alpha$ and IL-8 levels were decreased after FKN siRNA treatment $(\mathrm{P}<0.05)$. Furthermore, western blotting and RT-PCR analysis showed that FKN protein and mRNA levels were decreased after injection with FKN siRNA $(\mathrm{P}<0.05)$. Immunohistochemistry also showed that inflammation was decreased after injection with FKN-siRNA in the SAP rat model. Treatment with siRNA can inhibit FKN overexpression and also suppresses inflammation development in a SAP rat model. More importantly, this study indicated that FKN, which is overexpressed in the SAP rat model, may serve as a novel and effective therapeutic target for SAP.
\end{abstract}

Correspondence to: Dr Yao Zong Yuan, Department of Gastroenterology, Ruijin Hospital, Shanghai Jiaotong University School of Medicine, Shanghai 200025, P.R. China

E-mail: yyz28@medmail.com.cn

Present addresses: Departments of ${ }^{2}$ Gastroenterology and ${ }^{3}$ Gastroenterology Surgery, Affiliated Hospital of Ningxia Medical University, Yinchuan, Ningxia Hui Autonomous Region 750004, P.R. China

Key words: fractalkine, RNA interference, AR42J cell, inflammation, sever acute pancreas

\section{Introduction}

Severe acute pancreatitis (SAP) occurs in up to $20 \%$ of patients with acute pancreatitis (AP) and it has a high mortality rate $(1,2)$. In general, SAP develops in two phases. The first two weeks after the onset of symptoms are characterized by the systemic inflammatory response syndrome (SIRS). Release of proinflammatory mediators is thought to contribute to the pathogenesis of SIRS associated pulmonary, cardiovascular, and renal insufficiency (3). These systemic manifestations of a disease initially limited to the pancreas are thought to be mediated by a variety of proand anti-inflammatory mediators released from the pancreas and various other sources during the course of the disease. Cytokines and chemokines play a crucial role in SAP (4). If we prevent or decrease the release of inflammatory mediators, the prognosis of SAP will be better.

Fractalkine $(\mathrm{FKN})$ is the unique member of the CX3C chemokine subfamily. It exists in two forms, each mediating distinct biological actions. The membrane-anchored protein, which is primarily expressed on the inflamed endothelium, serves as an adhesion protein promoting the retention of monocytes and $\mathrm{T}$ cells in inflamed tissue. The soluble form more closely resembles a conventional chemokine and strongly induces chemotaxis. Based on this function, FKN acts as both an adhesion molecule and a chemoattractant. Thus, FKN plays a crucial role in the initiation and progression of inflammation (5-7). Several studies have reported that FKN plays an important role in inflammatory diseases, including rheumatoid arthritis (8), atherosclerosis (9), acute hepatitis (10) and kidney diseases (11). Our previous studies proved that FKN was overexpressed in the SAP rat model. We hypothesized that the SAP prognosis would be better after suppressing FKN overexpression.

RNA interference (RNAi) was first identified in 1998 and subsequently in mammalian cells as a post-transcriptional gene silencing mechanism (12). RNAi is a mechanism for RNA-guided regulation of gene expression in which doublestranded ribonucleic acid (dsRNA) results in rapid destruction of mRNA containing the identical sequence as the dsRNA (13). RNA interference mediated by siRNA is an important defense mechanism that binds to complementary target mRNA, while specifically targeting these sequences for degradation, resulting in the inhibition of protein expression to prevent 
and/or treat disease. siRNA has already been demonstrated as a potent therapy for targeting a wide variety of diseases (14-16). In addition, siRNA technology has been extensively tested against inflammation diseases in animal models (17). RNAi has developed within a decade into a tool for functional molecular genetics, target gene validation in drug discovery, and a novel therapeutic strategy $(18,19)$.

In this study, we used siRNA to target FKN and observed its influence on the biological functions of cerulein-stimulated AR42J cells. Furthermore, we employed siRNA to target FKN overexpression and assessed its ability to suppress inflammation development in SAP rats.

\section{Materials and methods}

Cell culture. The rat pancreatic acinar cell line, AR42J (ATCC, Rockville, MD, USA), was cultured in DMEM (Gibco-BRL, Gaithersburg, MD, USA) plus $10 \%$ fetal bovine serum (Gibco-BRL) and 1\% penicillin/streptomycin (Sigma, St. Louis, MO, USA) in standard conditions $\left(37^{\circ} \mathrm{C}\right.$ and $5 \%$ $\mathrm{CO}_{2}$ ). The AR42J cells were plated at a density of $3 \times 10^{5} / \mathrm{ml}$ in a 6 -well culture plate and allowed to attach for $12 \mathrm{~h}$. The cells were stimulated with cerulein $\left(10^{-8} \mathrm{M}\right)$ for $12 \mathrm{~h}$.

Transfection with siRNA. The adenoviral constructs carrying siRNA against FKN were designed and constructed by MingHong Co., Ltd., Shanghai, China. The specific silencing of the rat FKN gene expression was achieved by the siRNA technique. The FKN siRNA sequences were 5'-GCA ACA TCA CGT GCC ACAA-3' and 5'-TTG TGG CAC GTG ATG TTGC-3'. The cerulein-stimulated AR42J cells $\left(3 \times 10^{5} /\right.$ well $)$ were transfected with siRNA $(10 \mathrm{nmol} / \mathrm{ml})$ in 6 -well plates following the manufacturer's protocol.

Detection of pancreatic amylase and lactate dehydrogenase $(\mathrm{LDH})$ release by chromatometry. Cerulein-stimulated AR42J cells culture supernatant was collected by centrifugation and analyzed according to the operation manual of the pancreatic amylase test kit and LDH detection kit (Jiancheng Biotech, Nanjing, China).

Colony formation assay in soft agar. The standard colony formation assay was performed as described previously (20). The cerulein stimulated AR42J cells were transfected without (mock) or with siRNA targeting FKN. After 14 days of culture, crystal violet-stained colonies ( $>50$ cells/colony) were counted under a dissecting microscope. The plating efficiency (PE) represents the percentage of cells seeded that grow into colonies under a specified culture condition. The survival fraction, expressed as a function of irradiation, was calculated as follows: survival fraction $=$ colonies counted $/$ (cells seeded $\mathrm{x}$ $\mathrm{PE} / 100)$.

3-(4,5-dimethylthiazol-2-yl)-2,5-diphenyltertrazolium bromide (MTT) analysis of FKN siRNA in cultured cells. Ceruleinstimulated AR42J cells were transfected with FKN siRNA. Twelve hours after transfection, the cells were split into 96-well culture plates and incubated for 24,48 and $72 \mathrm{~h}$. The viable cells were then determined with the MTT assay. For the MTT assay, $20 \mu \mathrm{l}$ MTT (Sigma) stock solution $(5 \mathrm{mg} / \mathrm{ml})$ was added to each well on the plate. Cells were incubated for $4 \mathrm{~h}$ with MTT at $37^{\circ} \mathrm{C}$ and then lysed in $100 \mathrm{ml}$ of dimethylsulfoxide (DMSO). The intensity of the color developed, which is the reflection of number of live cells, was determined by a microplate reader at a $570-\mathrm{nm}$ wavelength. All values were compared to the corresponding controls. All assays were performed with 5 replicates.

Determination of FKN, IL-8 and TNF- $\alpha$ expression in AR42J cells by western blotting. The cerulein stimulated AR42J cells were randomly allocated into 3 groups: the phosphate-buffered saline (PBS)-treated group $(25 \mu \mathrm{l})$, the negative siRNA and FKN siRNA groups. The cells were washed twice with PBS and then homogenized in RIPA buffer (Shanghai Biocolor BioScience and Technology Co., Shanghai, China). Following centrifugation at $12,000 \mathrm{x}$ g at $4^{\circ} \mathrm{C}$ for $10 \mathrm{~min}$, the supernatant was collected and stored at $-80^{\circ} \mathrm{C}$. The protein concentration of each sample was determined by the BCA protein assay. Each sample was adjusted up to the desired protein content of $40 \mu \mathrm{g}$. Western blotting was performed as previously described (21) with minor modifications. The membrane was incubated with primary antibodies against FKN, IL- 8 and TNF- $\alpha$ (diluted, 1:1,000; Santa Cruz Biotechnology, Inc., Santa Cruz, CA, USA) overnight at $4^{\circ} \mathrm{C}$ followed by a peroxidase-conjugated anti-IgG (diluted, 1:2,000; Santa Cruz Biotechnology, Inc.) secondary antibody for $1 \mathrm{~h}$. GAPDH was determined in a similar manner with anti-GAPDH antibody (diluted 1:2,000; Santa Cruz Biotechnology, Inc.) as an endogenous control for other proteins. Western blotting was analyzed by scanning densitomertry using the Bio-Image analysis system (Bio-Rad, Baltimore, MD, USA) for quantification.

Animal model of SAP. Sprague-Dawley (SD) rats (220-250 g) were provided by the Experimental Animal Center of Ruijin Hospital, Shanghai Jiaotong University School of Medicine, Shanghai, China. The rats were deprived of food but were allowed access to water for $12 \mathrm{~h}$ before the operation. The rats were anaesthetized with an intraperitoneal administration of sodium pentobarbital $(30 \%, 0.15 \mathrm{ml} / 100 \mathrm{~g})$. The biliopancreatic duct was cannulated through the duodenum and the hepatic duct was closed by a small clamp. The SAP rats were induced by retrograde perfusion of $5 \%$ sodium taurocholate (Sigma) in a volume of $1.5 \mathrm{ml} / \mathrm{kg}$, using a perfusion pump (22). The control rats received an intraperitoneal injection of saline solution. The experiments were conducted according to the Guidelines of the Shanghai Animal Use and Care Committees and the National Animal Welfare Law.

In vivo SAP studies. FKN siRNA $((20 \mu \mathrm{g} / 100 \mathrm{~g})$ was injected once $24 \mathrm{~h}$ prior to the first injection of sodium taurocholate to the rats. The injected taurocholate SAP rat models were randomly divided into 3 groups ( $n=5$ for each group): mock (no siRNA), negative FKN siRNA, FKN siRNA. The mock group used PBS instead of siRNA. SAP sats were sacrificed under anesthesia $48 \mathrm{~h}$ after injecting of FKN siRNA. Blood was collected by abdominal aorta puncture. After centrifugation for $10 \mathrm{~min}$ at $2,500 \mathrm{x} \mathrm{g} / \mathrm{min}$, the supernatant of the blood was placed into sterilized EP tubes and stored in a refrigerator at $-20^{\circ} \mathrm{C}$. Meanwhile, pancreas and lung tissue frozen in a refrigerator at $-80^{\circ} \mathrm{C}$ until biochemical assays were performed. 


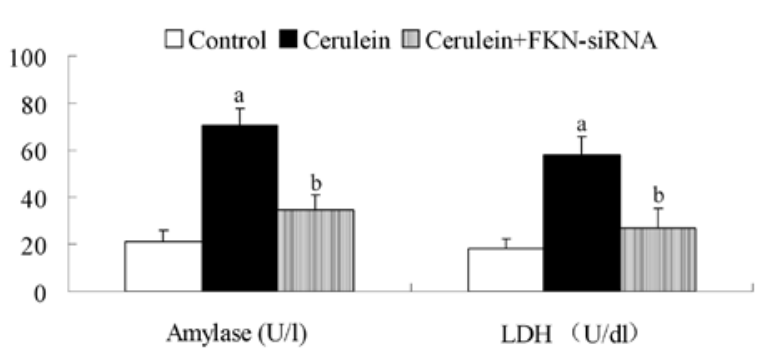

Figure 1. Release of amylase and LDH by cerulein-stimulated AR42J cells were detected by chromatometry. ${ }^{\mathrm{a}} \mathrm{P}<0.05$ vs. the control group; ${ }^{\mathrm{b}} \mathrm{P}<0.05$ vs. the cerulein group.

Animal model assessment. Tissue samples were fixed in $4 \%$ formaldehyde overnight and subsequently dehydrated through a graded ethanol series. After impregnation in paraffin wax, tissue samples were cut into blocks $(4 \mu \mathrm{m})$. Pancreas and lung tissue were stained with hematoxylin-eosin and examined by light microscopy. Sections were examined by an experienced histologist who was not aware of the sample identity for tissue injury. For this study, 5 randomly chosen microscopic fields were examined for each tissue sample and the histological score of pancreatic injury was calculated by a previously described method (23). Serum amylase activity was determined by spectrophotometric assay using the AMS detection kit (Jiancheng Biotech). Pancreatic tissue neutrophilic infiltration was assessed by measuring myeloperoxidase (MPO) activity, using the MPO detection kit (Jiancheng Biotech) (24).

Enzyme-linked immunosorbent assay (ELISA). Cell culture supernatants and the serum levels of FKN, TNF- $\alpha$ and IL-8 were examined with ELISA assay kits (Mai Bio Co., Ltd., Shanghai, China). Analyses were performed according to the instructions of the manufacturer (24).

FKN expression in SAP by western blot analysis. Pancreas and lung tissue proteins were extracted with RIPA buffer. Western blot analysis was performed as previously described.

FKN expression in SAP by RT-PCR. The total-RNA of pancreas and lung tissue was extracted with TRIzol (Takara Biotechnology Co., Ltd. China) reagent for each group. The cDNA was synthesized using the Prime Script ${ }^{\mathrm{TM}}$ RT reagent kit (Takara Biotechnology Co., Ltd.), and the reverse transcription was then performed on $1 \mu \mathrm{g}$ RNA sample by adding PrimeScript reagents. After reverse transcription, the RT-PCR reactions were performed in $25 \mu \mathrm{l}$ volumes. The primers were as follows: the primer sequence of FKN (141 bp); forward, 5'-CTG CCC TGA CTA GAA ATG GT-3' and reverse, 5'-CAG TCG GTT CCA AAG TAA GG-3'; The primer sequence of GAPDH (460 bp): forward, 5'-ACC ACA GTC CAT GCC ATC AC-3' and reverse, 5'-TCC ACC ACC CTG TTG CTG TA-3'. The band densities were normalized to the GAPDH band densities and the results were expressed as the ratio. The densities of the cDNA bands were analyzed by scanning densitometry using the Gel Doc 2000 software (Bio-Rad).

Immunohistochemical staining analysis. Sections embedded in paraffin wax were dewaxed, rehydrated in gradient alcohol, and endogenous peroxidase activity was blocked with $3 \% \mathrm{H}_{2} \mathrm{O}_{2}$

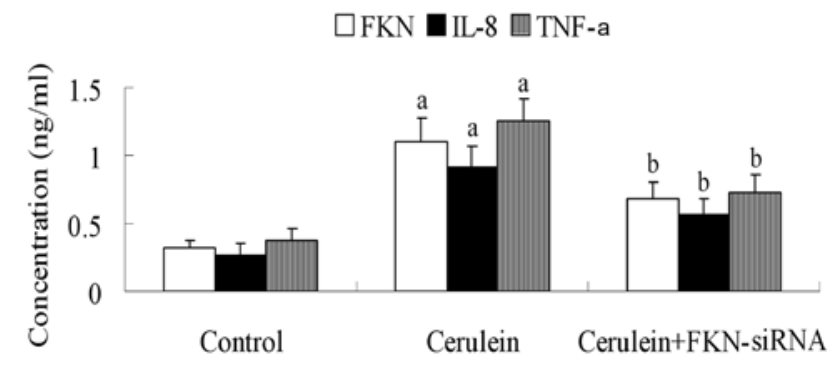

Figure 2. FKN, IL-8 and TNF- $\alpha$ levels in cerulein-stimulated AR42J cells. ${ }^{\mathrm{a}} \mathrm{P}<0.05$ vs. the control group; ${ }^{\mathrm{b}} \mathrm{P}<0.05$ vs. the cerulein group.

for $5 \mathrm{~min}$. Subsequently, a polyclonal FKN antibody (diluted 1:100, Santa Cruz Biotechnology, Inc.) that could recognize the amino-terminal sequences was applied overnight at $4^{\circ} \mathrm{C}$, followed by the UltraSensitive ${ }^{\mathrm{TM}}$ SP kit (Maixin-Bio, Fujian, China). At last, binding was visualized by diaminobenzidine (DAB) and the sections were counterstained with hematoxylin. Positive signals were detected as cytoplasm and nucleus staining presenting yellow color.

Statistics. All data are expressed as the mean \pm standard deviation (SD). Statistics were performed by the SPSS program 11.0 version (SPSS, Chicago, IL, USA). The one-way analysis of variance (ANOVA) with Dunnett's multiple comparison tests was used for comparisons. $\mathrm{P}<0.05$ indicated statistically significant differences.

\section{Results}

Release of amylase and LDH in cerulein-stimulated AR42J cells. Amylase is synthesized and stored in acinar cells of the pancreas. LDH is an enzyme of energy metabolism. Elevated activities of these enzymes in the plasma are generally considered markers of acute pancreatic injury. We found that in the control group amylase and LDH release levels were relatively low. In ceruleinstimulated AR42J cells, the release levels of the two enzymes were significantly higher compared with the control group $(\mathrm{P}<0.05)$. Furthermore, the levels of amylase and LDH were decreased after FKN siRNA treatment $(\mathrm{P}<0.05)$ (Fig. 1).

FKN, IL-8 and TNF- $\alpha$ levels in cerulein-stimulated AR42J cells. To determine the release of FKN, IL- 8 and TNF- $\alpha$ in cerulein-stimulated AR42J cells, we used ELISA to examine cell culture supernatants after FKN siRNA treatment. FKN was significantly decreased after FKN siRNA treatment $(\mathrm{P}<0.05)$ (Fig. 2). At the same time, the results showed that FKN siRNA inhibited the expression of IL-8 and TNF- $\alpha$.

Effect of FKN siRNA on cell growth. To determine whether FKN siRNA actually affected growth of cerulein-stimulated AR42J cells, we examined the growth curves of the cells in response to FKN siRNA treatment. FKN siRNA did not decrease the cell number as compared with the cerulein-stimulated AR42J cells (Fig. 3A). FKN siRNA promoted cerulein-stimulated AR42J cell growth on soft agar (Fig. 3B).

FKN overexpression is suppressed in cerulein-stimulated AR42J cells by siRNA targeting. To address if FKN can serve 
A

A

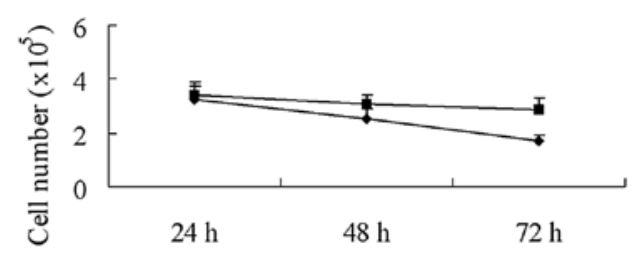

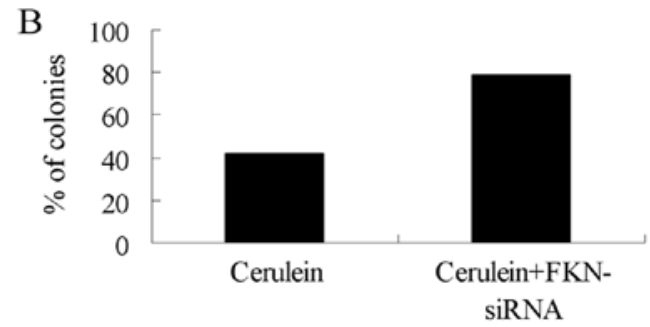

Figure 3. (A) Growth curves of cerulein-stimulated AR42J cells in response to FKN siRNA. The viable cells were counted at the indicated time points after transfection of FKN siRNA. (B) Colony formation in soft agar of cerulein stimulated AR42J cells in response to FKN siRNA.
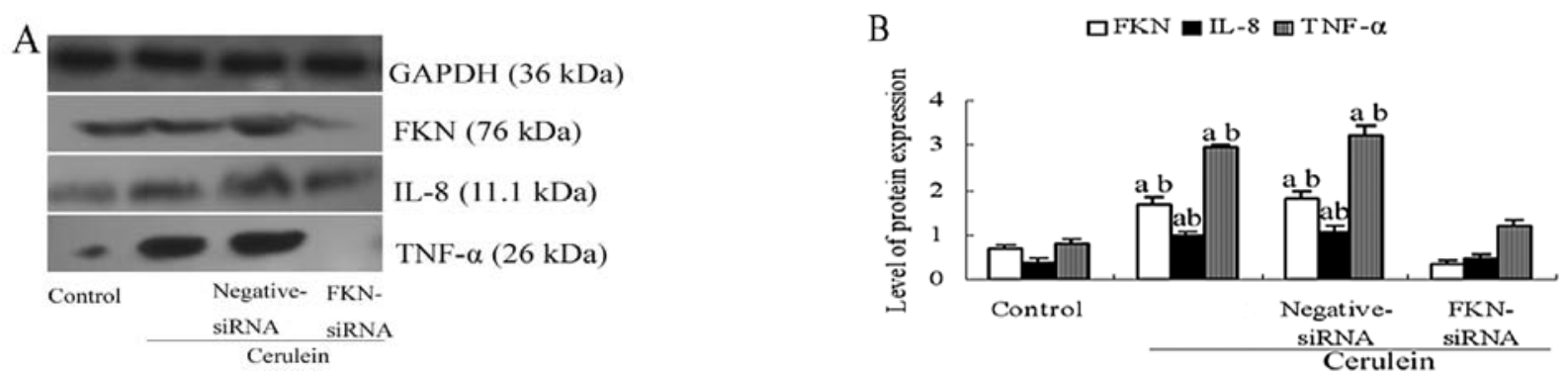

Figure 4. FKN siRNA suppresses FKN overexpression in cerulein-stimulated AR42J cells. (A) Representative western blot analysis in the AR42J cells detected with FKN, IL-8, TNF- $\alpha$ and GAPDH antibodies in each group. (B) Protein levels of FKN, IL-8 and TNF- $\alpha$ (measured as the ratio of FKN, IL-8, TNF- $\alpha$ to GAPDH by band density) in each group. ${ }^{\mathrm{a}} \mathrm{P}<0.05$ vs. the control group; ${ }^{\mathrm{b}} \mathrm{P}<0.05$ vs. the FKN siRNA + cerulein group.

Table I. Serum amylase, pancreatic MPO activity, and histological score of pancreatic injury in the SAP rat model.

\begin{tabular}{lccc}
\hline & Control & SAP & SAP treated FKN-siRNA \\
\hline Serum amylase (U/dl) & $7.86 \pm 0.084$ & $72 \pm 2.88^{\mathrm{a}}$ & $14.83 \pm 2.85^{\mathrm{b}}$ \\
Pancreatic MPO activity (U/g) & $0.046 \pm 0.0038$ & $1.13 \pm 0.064^{\mathrm{a}}$ & $0.32 \pm 0.023^{\mathrm{b}}$ \\
Histological score of pancreatic injury & $0.4 \pm 0.24$ & $10.4 \pm 0.89^{\mathrm{a}}$ & $4.2 \pm 0.36^{\mathrm{b}}$ \\
\hline
\end{tabular}

Values are means $\pm \mathrm{SD} ;{ }^{a} \mathrm{P}<0.05$ vs. the control group; ${ }^{\text {b }}<0.05$ vs. the $\mathrm{SAP}$ group.

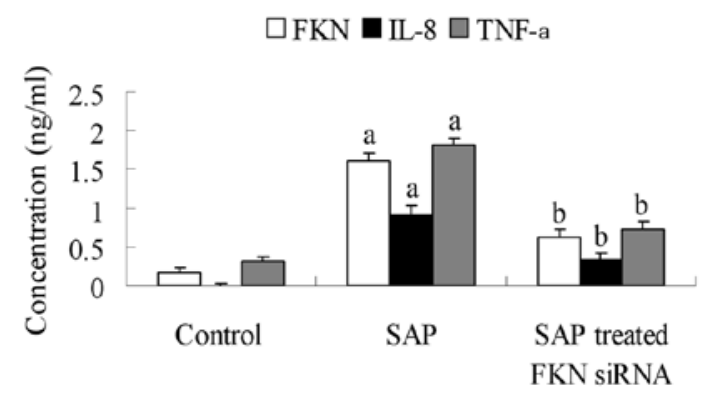

Figure 5. Serum FKN, IL-8 and TNF- $\alpha$ concentration of each group. ${ }^{a} \mathrm{P}<0.05$ vs. the control group; ${ }^{\mathrm{P}}<0.05$ vs. the $\mathrm{SAP}$ group.

as a novel therapeutic target for SAP, we first used siRNA to deplete FKN expression in cerulein-stimulated AR42J cells. The siRNA was transfected into cerulein-stimulated AR42J cells. The protein levels of FKN were reduced by FKN siRNA (Fig. 4). Furthermore, the inhibitory effect of the FKN siRNA affected the expression of IL-8 and TNF- $\alpha$ (Fig. 4). We found that the expression of IL- 8 and TNF- $\alpha$ protein were reduced after transfection with FKN siRNA. These data indicate that
FKN siRNA can effectively suppress the overexpression of FKN.

FKN siRNA treatment is able to suppress inflammation in vivo. To determine whether FKN siRNA could suppress inflammation in vivo, we established the SAP rat model and treated tha rats with FKN siRNA. All SAP rats were sacrificed under anesthesia at $48 \mathrm{~h}$ after treatment with FKN siRNA or sham operation. Serum amylase levels and MPO activity are shown Table I. Serum amylase and MPO activity were significantly elevated compared with the control group $(\mathrm{P}<0.05)$. The histological score of pancreatic injury indicated there were no remarkable pathologic changes in control rats. In the SAP groups, interstitial edema, inflammatory cell infiltration, focal necrosis and interstitial hemorrhage were observed. The histological score of pancreatic injury was significantly elevated compared with the control group $(\mathrm{P}<0.05)$. More importantly, we observed serum amylase levels and MPO activities were decreased after FKN siRNA treatment. We used ELISA to detect the serum levels of FKN, TNF- $\alpha$ and IL- 8 . The values of serum FKN, TNF- $\alpha$ and IL- 8 in each group are shown in Fig. 5. Serum FKN levels were significantly greater in the SAP 

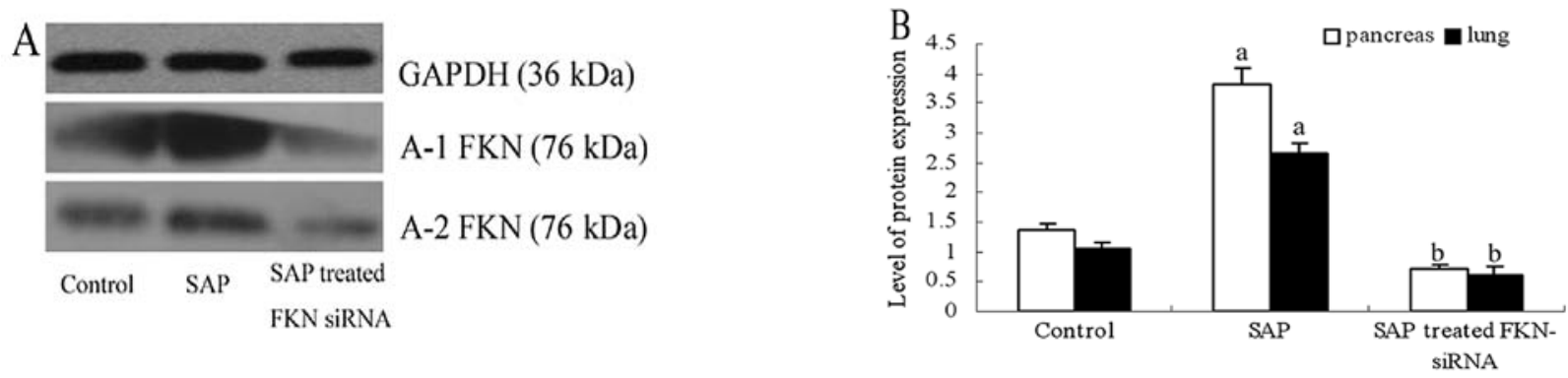

Figure 6. FKN protein expression in pancreas and lung tissues in different groups. (A) Representative western blot analysis of FKN in pancreas tissue (A-1) and lung tissue (A-2). (B) Protein levels of FKN (measured as the ratio of FKN to GAPDH by band density in different groups). ${ }^{\text {a }}<0.05$ vs. the control group; ${ }^{\mathrm{b}} \mathrm{P}<0.05$ vs. SAP group.
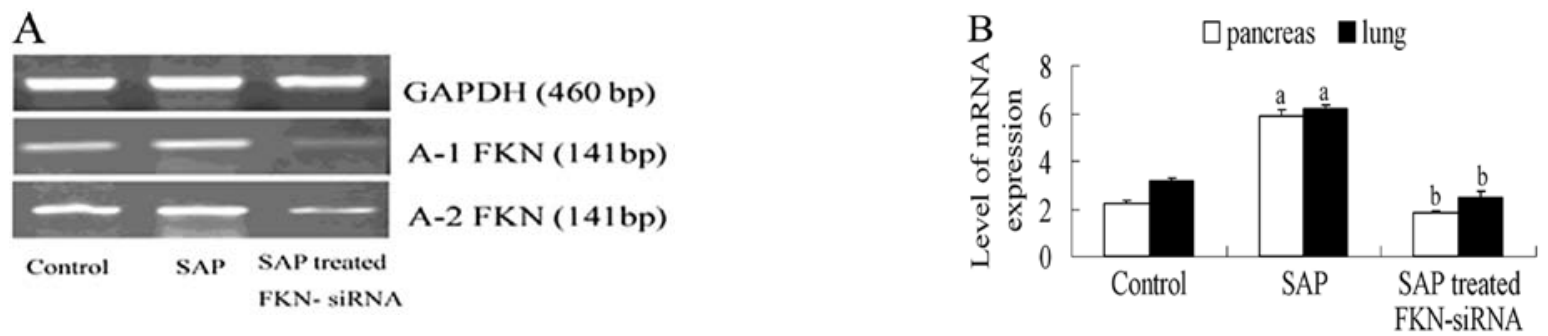

Figure 7. FKN mRNA expression in the pancreas and lung tissues in different groups. (A) Representative RT-PCR of FKN mRNA in pancreas tissue (A-1) and lung tissue (A-2). (B) mRNA levels of FKN (measured as the ratio of FKN to GAPDH by band density in different group). ${ }^{a} \mathrm{P}<0.05$ vs. the control group; ${ }^{\mathrm{b}} \mathrm{P}<0.05$ vs. the SAP group.
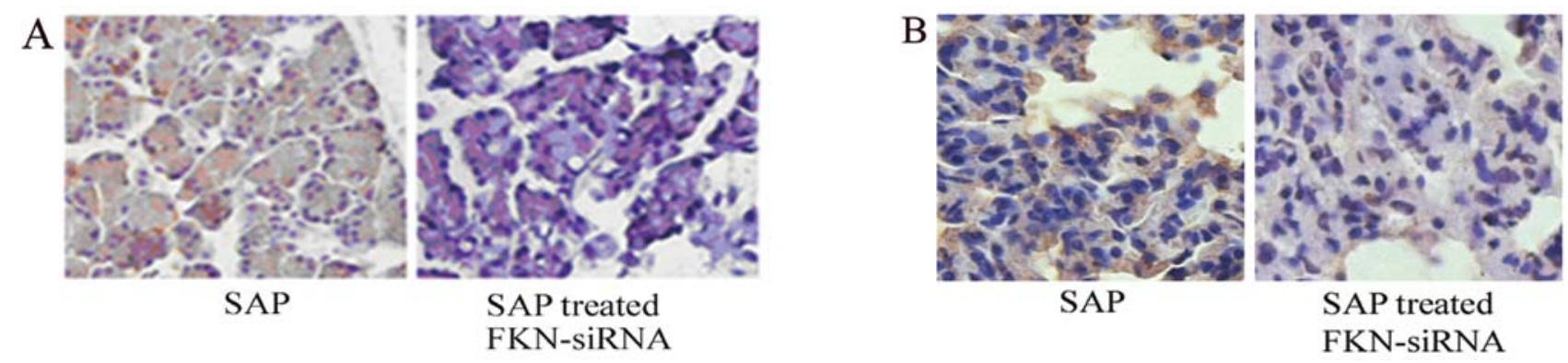

Figure 8. Confirmation of reduced FKN expression and inhibition of inflammation in response to FKN siRNA treatment by immunostaining. (A) Pancreas tissue (x40); (B) lung tissue (x40).

compared with the control group $(\mathrm{P}<0.05)$. Serum TNF- $\alpha$ and IL-8 levels were both elevated in the SAP compared with the control group $(\mathrm{P}<0.05)$. The values of serum FKN, TNF- $\alpha$ and IL- 8 were decreased after induction with FKN siRNA compared with the SAP group $(\mathrm{P}<0.05)$. In addition, western blotting and RT-PCR analysis showed that FKN protein and mRNA levels of pancreas and lung tissues were also decreased in the SAP rat model (Figs. 6 and 7). Furthermore, immunohistochemistry showed that FKN decreased after injection of FKN-siRNA in SAP rat model (Fig. 8). These results showed that treatment with FKN siRNA can inhibit inflammation development in SAP rats, indicating that FKN siRNA may serve as a novel therapeutic agent for treating SAP.

\section{Discussion}

Chemokines are small secreted proteins that stimulate the directional migration of leukocytes, playing a key role in the inflammatory response and infectious diseases (25). In a variety of pathological conditions, FKN may cause excessive attraction and activity of cytotoxic lymphocytes, which might lead to vascular and tissue damage (26). FKN is aberrantly expressed in many inflammatory diseases (8-11). Moreover, studies in animal models have shown that FKN inhibition may delay the initiation and progression of lupus nephritis (27). Cockwell et al (28) have previously reported increased mRNA levels of FKN in renal biopsies from patients with antineutrophil cytoplasmic antibody-positive vasculitic glomerulonephritis. Bjerkeli et al (29) have reported that increased CX3CL1/CX3CR1 interaction could be involved in the pathogenesis of the granulomatous vasculitis characterizing Wegener's granulomatosis patients. This study was aiming to prove that FKN may be involved in the pathogenesis of SAP. Furthermore, the present study clearly demonstrated a promising therapeutic potential of FKN siRNA for the treatment of FKN-overexpressing SAP. 
FKN displays distinctive biological activities compared to the other members of the chemokine family. It is a unique membrane-bound molecule expressed on endothelial cells, possessing a chemokine domain and an extended mucin-like stalk that allows it to function as both a chemoattractant and an adhesion molecule (30). The expression of FKN on the endothelium is generally low in healthy individuals in the absence of an inflammatory insult, but the expression of both the membrane-bound and the secreted form is greatly induced by inflammatory cytokines (5). Membrane-bound FKN can act as an adhesion molecule to mediate firm adhesion by binding with its receptor on leukocytes $(7,30)$. This membrane-bound form can be cleaved by metalloproteinases (31) to create circulating soluble FKN, a potential chemoattractant. TNF- $\alpha$ and IL-8 have been recognized to be important factors in the progression of SAP $(4,32)$. TNF- $\alpha$ can lead to injured pancreatic duct cells, pancreatic acinus ischemia, necrosis and inflammation (32). Many cell lines in the presence of activated neutrophils can release IL-8. IL-8 acts as the main secondary mediator of TNF- $\alpha$-induced neutrophil activation $(33,34)$. Our studies demonstrated the markedly elevated levels of FKN, IL-8 and TNF- $\alpha$ in cerulein-stimulated AR42J cells. These could potentially reflect pancreatic acinar cell-related inflammation in the SAP lesions. Moreover, the increased expression of FKN in the pancreas, as shown by both western blotting and RT-PCR, could facilitate migration of leukocyte subsets into the SAP lesions through FKN.

The adenovirus-mediated method of transferring siRNA has shown this method to be a more efficient delivery mechanism $(35,36)$. In this study, we utilized an adenovirus-mediated method to transfer siRNA, used FKN siRNA to target FKN overexpression and assessed its ability to suppress inflammation in cerulein-stimulated AR42J cells. This study revealed that FKN siRNA effectively inhibited FKN overexpression. TNF- $\alpha$ and IL-8, as primary inflammatory factors, directly injured cells of multiple organs, and caused ischemia, hemorrhage, necrosis, inflammation and edema $(33,37)$. FKN siRNA also effectively inhibited TNF- $\alpha$ and IL-8 overexpression in cerulein-stimulated AR42J cells and in the SAP rat model.

Recently, various approaches have been adapted to chemically modify the siRNAs to increase their nuclease resistance as well as intracellular uptake $(38,39)$. Thus, it will be of great interest to test if chemical modifications of our FKN siRNA will improve its therapeutic efficacy, especially for systematic treatment in the rat. In this study, we used FKN siRNA to target FKN overexpression and assessed its ability to suppress inflammation in the SAP rat model. Our results revealed that FKN siRNA effectively inhibited the FKN overexpression in ceruleinstimulated AR42J cells. Depletion of FKN promoted growth of FKN-overexpressing cells and blocked their proliferation. We also showed that FKN siRNA inhibited inflammation in the SAP rat model. Thus, our study clearly demonstrates the therapeutic potential of FKN siRNA for treating FKN-overexpressing SAP.

Acute lung injury is the most common extrapancreatic complication of SAP. The pathogenesis of lung injury is complex and probably involves multiple mechanisms, but mounting evidences point to the role of chemokines in the pathogenesis of SAP lung injury $(40,41)$. The expression of FKN on the endothelium is generally low in healthy individuals in the absence of an inflammatory insult, but the expression of both the membrane-bound and the secreted form is greatly induced by inflammatory cytokines (5). FKN may induce pulmonary vascular inflammatory cell recruitment and therefore, may promote inflammatory damage leading to abnormal scarring and remodeling of pulmonary arteries (42). Furthermore, this study showed that FKN was overexpressed in lung tissue and FKN siRNA inhibited the lung injury in SAP. The protein and mRNA levels of FKN were decreased after siRNA injection in lung tissue. We demonstrated that this was sufficient to inhibit FKN expression in vivo and as a result, led to SAP suppression. These results indicate that FKN, which is overexpressed in SAP, may serve as a novel and effective therapeutic target.

In conclusion, the present study validated systemic adenoviral siRNA delivery into cerulein-stimulated AR42J cells and the targeting of FKN in the SAP rat model. With foreseeable improvements in siRNA delivery and specificity, chemokines, such as FKN, may become attractive targets in the clinical therapy of inflammatory diseases.

\section{References}

1. Johnson CD and Abu-Hilal M: Persistent organ failure during the first week as a marker of fatal outcome in acute pancreatitis. Gut 53: 1340-1344, 2004.

2. Takeyama Y: Significance of apoptotic cell death in systemic complications with severe acute pancreatitis. J Gastroenterol 40: 1-10, 2005.

3. Johnson C, Kingsnorth A, Imrie C, et al: Double blind, randomised, placebo controlled study of a platelet activating factor antagonist, lexipafant, in the treatment and prevention of organ failure in predicted severe acute pancreatitis. Gut 48: 62-69, 2001.

4. Mayer J, Rau B, Gansauge F and Beger HG: Inflammatory mediators in human acute pancreatitis: clinical and pathophysiological implications. Gut 47: 546-552, 2000.

5. Umehara H, Bloom ET, Okazaki T, Nagano Y, Yoshie O and Imai T: Fractalkine in vascular biology: from basic research to clinical disease. Arterioscler Thromb Vasc Biol 24: 34-40, 2004.

6. Fong AM, Robinson LA, Steeber DA, et al: Fractalkine and CX3CR1 mediate a novel mechanism of leukocyte capture, firm adhesion, and activation under physiologic flow. J Exp Med 188: 1413-1419, 1998.

7. Imai T, Hieshima K, Haskell C, et al: Identification and molecular characterization of fractalkine receptor CX3CR 1 , which mediates both leukocyte migration and adhesion. Cell 91: 521-530, 1997.

8. Volin MV, Woods JM, Amin MA, Connors MA, Harlow LA and Koch AE: Fractalkine: a novel angiogenic chemokine in rheumatoid arthritis. Am J Pathol 159: 1521-1530, 2001.

9. Lee SJ, Namkoong S, Kim YM, et al: Fractalkine stimulates angiogenesis by activating the Raf-1/MEK/ERK- and PI3K/ Akt/eNOS-dependent signal pathways. Am J Physiol Heart Circ Physiol 291: H2836-H2846, 2006.

10. Efsen E, Grappone C, DeFranco RM, et al: Up-regulated expression of fractalkine and its receptor CX3CR1 during liver injury in humans. J Hepatol 37: 39-47, 2002.

11. Segerer S, Hughes E, Hudkins KL, Mack M, Goodpaster T and Alpers CE: Expression of the fractalkine receptor (CX3CR1) in human kidney disease. Kidney Int 62: 488-495, 2002.

12. Elbashir SM, Harborth J, Lendeckel W, Yalcin A, Weber K and Tuschl T: Duplexes of 21-nucleotide RNAs mediate RNA interference in cultured mammalian cells. Nature 411: 494-498, 2001.

13. Hannon GJ: RNA interference. Nature 418: 244-251, 2002.

14. Duxbury MS, Matros E, Ito H, Zinner MJ, Ashley SW and Whang EE: Systemic siRNA-mediated gene silencing: a new approach to targeted therapy of cancer. Ann Surg 240: 667-674, 2004.

15. Filleur S, Courtin A, Ali S, et al: SiRNA-mediated inhibition of vascular endothelial growth factor severely limits tumor resistance to antiangiogenic thrombospondin-1 and slows tumor vascularization and growth. Cancer Res 63: 3919-3922, 2003.

16. Song E, Lee SK, Wang J, et al: RNA interference targeting Fasprotects mice from fulminant hepatitis. Nat Med 9: 347-351, 2003. 
17. Sioud M: Advances in RNA sensing by the immune system: separation of siRNA unwanted effects from RNA inference. Methods Mol Biol 629: 33-52, 2010.

18. Leung RK and Whittaker PA: RNA interference: from gene silencing to gene- specific therapeutics. Pharmacol Ther 107: 222-239, 2005

19. Kim DH and Rossi JJ: Strategies for silencing human disease using RNA interference. Nat Rev Genet 8: 173-184, 2007.

20. Yulong L, Hong G, Shiaw-Yih L, Goss JA, Brunicardi FC and Li K: siRNA-based targeting of cyclin E over-expression inhibits breast cancer cell growth and suppresses tumor development in breast cancer mouse model. PLoS One 5: e12860, 2010.

21. Yubero S, Ramudo L, Manso MA and De Dios I: Mechanisms of dexamethasone-mediated chemokine down-regulation in mild and severe acute pancreatitis. Biochim Biophys Acta 1792: 1205-1211, 2009.

22. Chen P, Yuan Y, Wang S, Zhan L and Xu J: Captopril, an angiotensin-converting enzyme inhibitor, attenuates the severity of acute pancreatitis in rats by reducing expression of matrix metalloproteinase 9. Tohoku J Exp Med 209: 99-101, 2006.

23. Grewal HP, Mohey el Din A, Gaber L, Kotb M and Gaber AO: Amelioration of the physiologic and biochemical changes of acute pancreatitis using an anti-TNF-alpha polyclonal antibody. Am J Sug 167: 214-218, 1994.

24. Zhang XP, Zhang J, Ma ML, et al: Pathological changes at early stage of multiple organ injury in a rat model of severe acute pancreatitis. Hepatobiliary Pancreat Dis Int 9: 83-87, 2010.

25. Murphy PM: The molecular biology of leukocyte chemoattractant receptors. Annu Rev Immunol 12: 593-633, 1994.

26. Brueckmann $M$ and Borggrefe M: Therapeutic potential of fractalkine: a novel approach to metastatic colon cancer. Gut 56: 314-316, 2007.

27. Inoue A, Hasegawa $\mathrm{H}$, Kohno M, et al: Antagonist of fractalkine (CX3CL1) delays the initiation and ameliorates the progression of lupus nephritis in MRL/lpr mice. Arthritis Rheum 52: 1522-1533, 2005.

28. Cockwell P, Chakravorty SJ, Girdlestone J and Savage CO: Fractalkine expression in human renal inflammation. J Pathol 196: 85-89, 2002.

29. Bjerkeli V, Dama JK, Fevang B, Holter JC, Aukrust P and Froland SS: Increased expression of fractalkine (CX3CL1) and its receptor CX3CR1, in Wegener's granulomatosis-possible role in vascular inflammation. Rheumatology 46: 1422-1427, 2007.
30. Bazan JF, Bacon KB, Hardiman G, et al: A new class of membrane bound chemokine with a CX3C motif. Nature 385 : 640-644, 1997.

31. Hundhausen C,Misztela D,Berkhout TA, et al: The disintegrin-like metalloproteinase ADAM10 is involved in constitutive cleavage of CX3CL1 (fractalkine) and regulates CX3CL1-mediated cell-cell adhesion. Blood 102: 1186-1195, 2003.

32. Zhang XP, Wang L and Zhou YF: The pathogenic mechanism of severe acute pancreatitis complicated with renal injury: a review of current knowledge. Dig Dis Sci 53: 297-306, 2008.

33. Kingsnorth A: Role of cytokines and their inhibitors in acute pancreatitis. Gut 40: 1-4, 1997.

34. Al Mofleh IA: Severe acute pancreatitis: pathogenetic aspects and prognostic factors. World J Gastroenterol 14: 675-684, 2008.

35. Brummelkamp TR, Bernards R and Agami R: Stable suppression of tumorigenicity by virus-mediated RNA interference. Cancer Cell 2: 243-247, 2002.

36. Chetty C, Bhoopathi P, Joseph P, Chittivelu S, Rao JS and Lakka S: Adenovirus-mediated siRNA against MMP-2 suppresses tumor growth and lung metastasis in mice. Mol Cancer Ther 5: 2289-2299, 2006.

37. Sandberg AA and Borgstrom A: Early prediction of severity in acute pancreatitis: is this possible? JOP 3: 116-125, 2002.

38. Soutschek J, Akinc A, Bramlage B, et al: Therapeutic silencing of an endogenous gene by systemic administration of siRNAs. Nature 432: 173-178, 2004.

39. Goyal BR, Patel MM, Soni MK and Bhadada SV: Therapeutic opportunities of small interfering RNA. Fundam Clin Pharmacol 23: 367-386, 2009

40. Sochor M, Richter S, Schmidt A, Hempel S, Hopt UT and Keck T: Inhibition of matrix metalloproteinase-9 with doxycycline reduces pancreatitis-associated lung injury. Digestion 80: 65-73, 2009.

41. Chen C, Xu S, Wang WX, et al: Rosiglitazone attenuates the severity of sodium taurocholate induced acute pancreatitis and pancreatitis-associated lung injury. Arch Med Res 40: 79-88, 2009.

42. Perros F, Drofmuller P, Souza R, et al: Fractalkine-induced smooth muscle cell proliferation in pulmonary hypertension. Eur Respir J 29: 937-943, 2007. 